\title{
Surgical versus non-operative initial management of post-endoscopic retrograde cholangiopancreatography perforation: a systematic review and meta-analysis
}

\author{
Athina A. Samara, Alexandros Diamantis, Konstantinos Perivoliotis, Georgios Mavrovounis, \\ Dimitrios Symeonidis, loannis Baloyiannis, Dimitris Zacharoulis
}

University Hospital of Larissa, Greece

Abstract

Background In the present study we performed a systematic review and meta-analysis regarding the initial management of perforations following endoscopic retrograde cholangiopancreatography (ERCP).

Methods A systematic review and meta-analysis was conducted according to the Preferred Reporting Items for Systematic Reviews and Meta-Analyses (PRISMA) guidelines and the Cochrane Handbook for Systematic Reviews of Interventions.

Results In total, 10 comparative studies and 223 patients with post-ERCP perforations were included in the present study. In type I and II perforations, the success rate of initial surgical management was higher compared to the non-operative management $(\mathrm{NOM})$ group $(\mathrm{P}=0.09$ and $\mathrm{P}=0.02$, respectively). There was no statistically significant difference in mortality rates or length of hospital stay between initial surgical and NOM management for any type of perforation.

Conclusions The current meta-analysis demonstrated the significance of the initial management of patients with post-ERCP perforations. Whether a surgical or an endoscopic approach is chosen, the patient should immediately be evaluated by an experienced surgeon or endoscopist.

Keywords Endoscopic retrograde cholangiopancreatography complications, duodenal perforation, surgical management, iatrogenic duodenal injury

Ann Gastroenterol 2021; 34 (x): 1-11

\section{Introduction}

Since its introduction in the 1960s, endoscopic retrograde cholangiopancreatography (ERCP) has played both a diagnostic and a therapeutic role. Today, since the establishment of noninvasive diagnostic procedures such as magnetic resonance cholangiopancreatography (MRCP) and endoscopic ultrasound (EUS), ERCP has evolved to predominantly become a therapeutic tool in hepato-pancreato-biliary diseases [1]. While a safe method, ERCP is associated with considerable complications, such as pancreatitis, bleeding, cholangitis and duodenal perforation [2]. The latter is the most concerning of

Department of Surgery, University Hospital of Larissa, Greece

Conflict of Interest: None

Correspondence to: Athina A. Samara, Department of Surgery, University Hospital of Larissa, Greece, 41110, Mezourlo Hill, Greece, e-mail: at.samara93@gmail.com

Received 6 June 2021; accepted 20 July 2021; published online 12 October 2021

DOI: https://doi.org/10.20524/aog.2021.0671 all complications, with an estimated incidence ranging from $0.09-1.67 \%$ and mortality up to $8 \%$ [3].

Because of the rarity of this adverse event and the heterogeneity of patients, data in the literature are based on case series and there are no large prospective studies. Thus, initial management of post-ERCP perforations is still controversial, with no consensus among clinicians regarding optimal treatment. Traditionally, surgery was considered a more appropriate method of management for post-ERCP perforation; however, in the past decade a more selective approach has evolved, with both conservative and endoscopic management options being available [4]. There are only limited and isolated data available regarding surgical management, with controversial recommendations on the timing and type of surgical procedures. As a result, management tends to depend on an individual clinician's preference and expertise.

According to Stapfer et al [5], 4 classes of duodenal perforations, in descending order of severity, based on the mechanism, anatomical location and severity of the injury, may predict the need for surgery. More specifically, lateral or medial wall perforations (type I) caused by the endoscope are often large and remote from the ampulla, with intraperitoneal leakage, and require immediate 
surgery. In the present study we therefore aimed to perform a systematic review and meta-analysis of all the available literature and data regarding the initial management of perforations following ERCP.

\section{Materials and methods}

\section{Study protocol}

The present study was conducted in accordance with the Preferred Reporting Items for Systematic Reviews and Meta-Analyses (PRISMA) guidelines [6] and the Cochrane Handbook for Systematic Reviews of Interventions [7].

\section{Endpoints}

The primary endpoint of this meta-analysis was the success rate of initial management of post-ERCP perforations, comparing initial surgical and non-operative management (NOM). Secondary endpoints included the mortality rate and the overall length of stay.

\section{Eligibility criteria}

Literature considered as eligible included all comparative human prospective or retrospective studies that reported relevant and retrievable data on surgical and NOM of perforations following ERCP, evaluated in terms of the Stapfer classification [5]. Exclusion criteria included the following: 1) non-human trials; 2) irretrievable data; 3 ) pediatric patients; 4) non-English language; 5) non-comparative studies; 6) studies including less than 6 patients; 7) non-Stapfer classification; and 8 ) studies in the form of expert opinions, editorials, conference abstracts and letters.

\section{Literature search}

A systematic literature search was performed using the scholar databases Medline (PubMed), Scopus and Web of Science. The search included articles from the beginning of the databases to February $28^{\text {th }} 2021$; all studies published up to the last search date were included in the database screening.

The following Boolean search algorithm was applied:

- [ERCP] AND [perforation]

In addition, the reference lists of eligible studies were screened manually.

\section{Study selection and data collection}

After the removal of duplicate data, both titles and abstracts of the remaining studies were screened. This was followed by a full-text review. The literature screening, data extraction and quality assessment was completed blindly and in duplicate by 2 independent researchers (GM and AS). In the event that a discrepancy could not be resolved, the opinion of a third senior researcher was considered (DZ). Quality and methodology evaluation included the Case Series Quality Appraisal Checklist [8] for case-series studies.

\section{Statistical analysis}

Cochrane Collaboration RevMan version 5.4.1 was used for the completion of statistical analyses. Odds ratios and weighted mean differences were derived for categorical and continuous variables, respectively. All variables were reported with the respective $95 \%$ confidence interval. In cases where a trial did not provide the mean or standard deviation, these values were calculated from the reported median, range or interquartile range. The statistical methods applied were the MaentelHaenszel and the inverse variance methods for categorical and continuous variables, respectively. Based on the results of the Cochran Q test, either the random effects, or the fixed effects model was constructed. Heterogeneity was quantified in terms of $I^{2}$. Statistical significance was considered at the level of $\mathrm{P}<0.05$.

\section{Risk of bias across studies}

To evaluate the possible presence of publication bias, a funnel plot of the primary endpoint was visually inspected.

\section{Results}

The literature search resulted in the retrieval of 1725 records (Fig. 1). After the removal of 1080 duplicate records, 645 titles and abstracts were screened. A total of 591 articles were excluded, leaving 54 articles that underwent a full-text review. Most of the studies did not use the Stapfer classification, and as a result only 10 comparative studies [1,5,9-16] regarding the initial management of post-ERCP perforations were eligible for quantitative analysis.

The main characteristics of the included studies are presented in Table 1. Nine retrospective studies [1,5,9-10,12-16] and a retrospective review of a prospective database [11] were included in the quantitative analysis. Table 1 also displays demographics information. Six of the included case-series [5,10-11,14-16] were scored as $8 / 9$ and 4 studies $[1,9,12-13]$ as $7 / 9$ in the Case Series Quality Appraisal Checklist [8].

A total of 223 patients with post-ERCP perforations were identified and included in the present evaluation. The incidence of ERCP-related perforations was higher in studies with a small number of total ERCPs. Perforation type was classified according to the Stapfer classification [5]. Of the 58 patients identified with a type I perforation, 39 patients (67.2\%) underwent initial surgical management, while 19 (32.8\%) had 


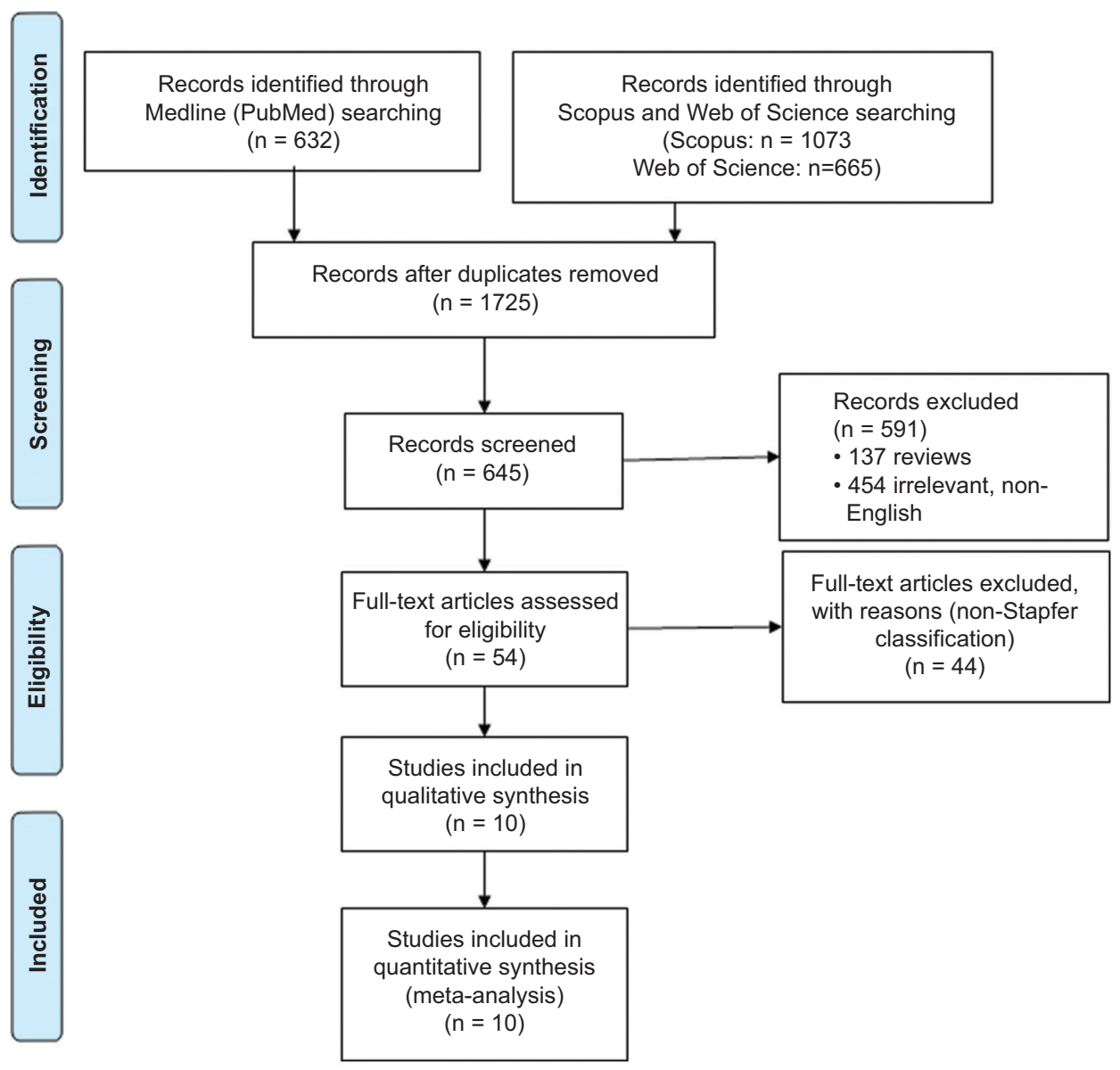

Figure 1 PRISMA flow diagram

Table 1 Study characteristics

\begin{tabular}{|c|c|c|c|c|c|c|c|}
\hline $\begin{array}{l}\text { First Author } \\
\text { [Ref.] }\end{array}$ & $\begin{array}{l}\text { Study } \\
\text { Period }\end{array}$ & Type of Study & $\begin{array}{l}\text { Number of } \\
\text { perforations }\end{array}$ & $\begin{array}{l}\text { Total } \\
\text { ERCPs }\end{array}$ & $\begin{array}{l}\text { Incidence of } \\
\text { perforation }\end{array}$ & Mean Age & Males/Females \\
\hline Mousa [9] & $2007-2017$ & Retrospective & 6 & 852 & $0.7 \%$ & 48.2 & $1 / 5$ \\
\hline Kumbhari [10] & $2000-2014$ & Retrospective & $61^{*}$ & 3331 & $1.8 \%$ & 51.3 & $12 / 49$ \\
\hline Kodali [11] & $2002-2012$ & $\begin{array}{l}\text { Retrospective review of } \\
\text { a prospective database }\end{array}$ & 12 & 8264 & $0.15 \%$ & 58.58 & $2 / 10$ \\
\hline Rabie [12] & 2008-2011 & Retrospective & 10 & 597 & $1.68 \%$ & 56.6 & $3 / 7$ \\
\hline Miller [1] & $1995-2011$ & Retrospective & 27 & 1638 & $1.64 \%$ & Median: $73.6(30-94)$ & $9 / 18$ \\
\hline Alfieri [13] & 1999-2011 & Retrospective & 30 & 14618 & $0.21 \%$ & Range 32-75 & $13 / 17$ \\
\hline Krishna [14] & 2001-2007 & Retrospective & 14 & N/A & N/A & 46 & $8 / 6$ \\
\hline Polydorou [15] & 1989-2010 & Retrospective & 44 & 9889 & $0.45 \%$ & Median: 62 & $11 / 33$ \\
\hline Avgerinos [16] & 1999-2008 & Retrospective & 15 & 4358 & $0.34 \%$ & Median: 69 (34-87) & $6 / 9$ \\
\hline Stapfer [5] & 1993-1998 & Retrospective & 14 & 1413 & $0.99 \%$ & 48.9 & $4 / 10$ \\
\hline
\end{tabular}

${ }^{\star} 76$ total perforations before the exclusion of type 3 and 4

ERCP, endoscopic retrograde cholangiopancreatography

initial NOM. In addition, 131 patients with type II perforation were included in the present study, with 13 (9.9\%) undergoing initial surgical management and 118 (90.1\%) undergoing initial NOM. There were 22 patients with a type III perforation; only $3(13.6 \%)$ were treated with surgery while the remaining 19 (86.4\%) underwent NOM. Finally, 20 patients with a type IV 
perforation were identified, and all of them $(n=20)$ were treated with initial NOM (Supplementary Table 1).

Table 2 summarizes the success rates of the initial management of post-ERCP perforations. Specifically, 31 of 39 patients $(79.5 \%)$ with type I perforation had a successful initial surgical treatment, and 10 of 19 patients (52.6\%) with type I perforation had a successful initial NOM. Ten of 13 patients $(76.9 \%)$ with type II perforation had a successful initial surgical treatment, and 88 of 118 patients (74.6\%) with type II perforation had a successful initial NOM. Concerning type III perforations, the success rate of initial management was $100 \%$ for both surgery and NOM (3/3 and 19/19, respectively). All patients with type IV perforation $(n=20)$ were treated with NOM, with $100 \%$ success.

Data regarding mortality are displayed in Table 3. Regarding type I perforations, the mortality rate was $15.4 \%(6 / 39)$ for the initial surgery group and $31.6 \%(6 / 19)$ for the NOM group. The mortality rate of patients with a type II perforation was $11.1 \%$ $(2 / 18)$ and $8 \%(9 / 113)$ for the initial surgery and NOM groups, respectively. No deaths were reported for either perforation type III or IV, so the mortality rate was zero for both groups.

Quantitative analysis of the primary outcome (success of initial management) was conducted in 3 subgroups relating to the type of perforation (Fig. 2). In type I perforations, the success rate of initial surgical management was higher when compared to the NOM group (79.5\% and $52.6 \%$, respectively); however, the difference was not statistically significant $(\mathrm{P}=0.09)$. Type II perforations displayed a statistically significant difference between the success rate of initial surgical and NOM management, favoring management with initial surgery $(\mathrm{P}=0.02)$. Results for type III perforations could not be evaluated, as the success rates were $100 \%$ in both groups and all the patients with type IV perforations were managed with NOM.
Regarding secondary outcomes, there was no statistically significant difference in mortality rates between initial surgical and NOM management for any type of perforation (Supplementary Fig. 1). Similarly, there was no statistically significant difference in the length of hospital stay between the 2 groups for any type of perforation (Supplementary Fig. 2). Visual inspection of the funnel plot of the primary endpoint revealed a symmetrical distribution of the included studies (Supplementary Fig. 3).

\section{Discussion}

During the last decade, because of the wide availability of noninvasive imaging techniques such as MRCP and EUS, the use of the invasive modality of ERCP has been limited to the management and treatment of various pancreatic and biliary pathologies and disorders [1,17]. Even though ERCP is a common procedure nowadays, it still remains a challenging endoscopic procedure, and safe application rates require adequately high expertise, level of training, and experience on the part of the endoscopists and their supporting team. While relatively safe in experienced hands, ERCP is still associated with morbidity and complications, such as pancreatitis, bleeding, and post sphincterotomy perforation, with a reported incidence of $0.08-10 \%$ [2-3]. Moreover, regarding the perforations, which are the most dangerous and life-threatening ERCP related complication, medicolegal issues may arise [18], usually related to the provision of information and the acquisition of consent, and to the distinction between not easily avoidable/preventable procedure consequence and medical error.

In the present study, therefore, we aimed to perform a systematic review and meta-analysis of all the available literature and data regarding the initial management of

Table 2 Success of initial management

\begin{tabular}{|c|c|c|c|c|c|c|c|c|c|c|c|c|}
\hline \multirow{3}{*}{$\begin{array}{l}\text { First Author } \\
\text { [Ref.] }\end{array}$} & \multicolumn{12}{|c|}{ Success of initial management } \\
\hline & \multicolumn{3}{|c|}{1} & \multicolumn{3}{|c|}{2} & \multicolumn{3}{|c|}{3} & \multicolumn{3}{|c|}{4} \\
\hline & Total & Surgery & NOM & Total & Surgery & NOM & Total & Surgery & NOM & Total & Surgery & NOM \\
\hline Mousa [9] & $1 / 3$ & $1 / 1$ & $0 / 2$ & $0 / 1$ & $0 / 1$ & - & $1 / 1$ & - & $1 / 1$ & $1 / 1$ & - & $1 / 1$ \\
\hline Kumbhari [10] & $6 / 7$ & $5 / 5$ & $1 / 2$ & $50 / 54$ & - & $50 / 54$ & - & - & - & - & - & - \\
\hline Kodali [11] & $2 / 2$ & $1 / 1$ & $1 / 1$ & $8 / 8$ & $3 / 3$ & $5 / 5$ & $2 / 2$ & - & $2 / 2$ & - & - & - \\
\hline Rabie [12] & $1 / 3$ & $1 / 2$ & $0 / 1$ & $1 / 1$ & - & $1 / 1$ & $3 / 3$ & - & $3 / 3$ & $3 / 3$ & - & $3 / 3$ \\
\hline Miller [1] & $3 / 5$ & $3 / 5$ & - & $4 / 12$ & $3 / 3$ & $1 / 9$ & $5 / 5$ & - & $5 / 5$ & $5 / 5$ & - & $5 / 5$ \\
\hline Alfieri [13] & $0 / 6$ & $0 / 2$ & $0 / 4$ & $4 / 15$ & $1 / 2$ & $3 / 13$ & $1 / 1$ & - & $1 / 1$ & $8 / 8$ & - & $8 / 8$ \\
\hline Krishna [14] & $11 / 11$ & $4 / 4$ & $7 / 7$ & $0 / 1$ & $0 / 1$ & - & $2 / 2$ & $2 / 2$ & - & - & - & - \\
\hline Polydorou [15] & $5 / 7$ & $4 / 6$ & $1 / 1$ & $25 / 30$ & - & $25 / 30$ & $5 / 5$ & - & $5 / 5$ & $2 / 2$ & - & $2 / 2$ \\
\hline Avgerinos [16] & $9 / 9$ & $9 / 9$ & - & $2 / 3$ & $2 / 2$ & $0 / 1$ & - & - & - & $1 / 1$ & - & $1 / 1$ \\
\hline Stapfer [5] & $3 / 5$ & $3 / 4$ & $0 / 1$ & $4 / 6$ & $1 / 1$ & $3 / 5$ & $3 / 3$ & $1 / 1$ & $2 / 2$ & - & - & - \\
\hline Total & $41 / 58$ & $31 / 39$ & $10 / 19$ & $98 / 131$ & $10 / 13$ & $88 / 118$ & $22 / 22$ & $3 / 3$ & $19 / 19$ & $20 / 20$ & - & $20 / 20$ \\
\hline
\end{tabular}

NOM, non-operative management 
Table 3 Mortality rate

\begin{tabular}{|c|c|c|c|c|c|c|c|c|c|c|c|c|}
\hline \multirow[t]{3}{*}{ First Author [Ref.] } & \multicolumn{12}{|c|}{ Mortality } \\
\hline & \multicolumn{3}{|c|}{1} & \multicolumn{3}{|c|}{2} & \multicolumn{3}{|c|}{3} & \multicolumn{3}{|c|}{4} \\
\hline & Total & Surgery & NOM & Total & Surgery & NOM & Total & Surgery & $\mathrm{NOM}$ & Total & Surgery & NOM \\
\hline Mousa [9] & $1 / 3$ & $0 / 1$ & $1 / 2$ & $1 / 1$ & $1 / 1$ & - & $0 / 1$ & - & $0 / 1$ & $0 / 1$ & - & $0 / 1$ \\
\hline Kumbhari [10] & $1 / 7$ & $0 / 5$ & $1 / 2$ & $1 / 54$ & - & $1 / 54$ & - & - & - & - & - & - \\
\hline Kodali [11] & $0 / 2$ & $0 / 1$ & $0 / 1$ & $0 / 8$ & $0 / 3$ & $0 / 5$ & $0 / 2$ & - & $0 / 2$ & - & - & - \\
\hline Rabie [12] & $1 / 4$ & $1 / 4$ & - & $0 / 1$ & - & $0 / 1$ & $0 / 3$ & - & $0 / 3$ & $0 / 3$ & - & $0 / 3$ \\
\hline Miller [1] & $2 / 5$ & $0 / 3$ & $2 / 2$ & $6 / 12$ & $0 / 3$ & $6 / 9$ & $0 / 5$ & $0 / 0$ & $0 / 5$ & $0 / 5$ & - & $0 / 5$ \\
\hline Alfieri [13] & $3 / 6$ & $2 / 2$ & $1 / 4$ & $1 / 15$ & $0 / 2$ & $1 / 13$ & $0 / 1$ & - & $0 / 1$ & $0 / 8$ & - & $0 / 8$ \\
\hline Krishna [14] & $0 / 11$ & $0 / 4$ & $0 / 7$ & $1 / 1$ & $1 / 1$ & - & $0 / 2$ & $0 / 2$ & - & - & - & - \\
\hline Polydorou [15] & $2 / 7$ & $2 / 6$ & $0 / 1$ & $0 / 30$ & - & $0 / 30$ & $0 / 5$ & - & $0 / 5$ & $0 / 2$ & - & $0 / 2$ \\
\hline Avgerinos [16] & $0 / 9$ & $0 / 9$ & - & $1 / 3$ & $0 / 2$ & $1 / 1$ & - & - & - & $0 / 1$ & - & $0 / 1$ \\
\hline Stapfer [5] & $2 / 5$ & $1 / 4$ & $1 / 1$ & $0 / 6$ & $0 / 1$ & $0 / 5$ & $0 / 3$ & $0 / 1$ & $0 / 2$ & - & - & - \\
\hline Total & $12 / 58$ & $6 / 39$ & $6 / 19$ & $11 / 131$ & $2 / 18$ & $9 / 113$ & $0 / 22$ & $0 / 3$ & $0 / 19$ & $0 / 20$ & - & $0 / 20$ \\
\hline
\end{tabular}

NOM, non-operative management

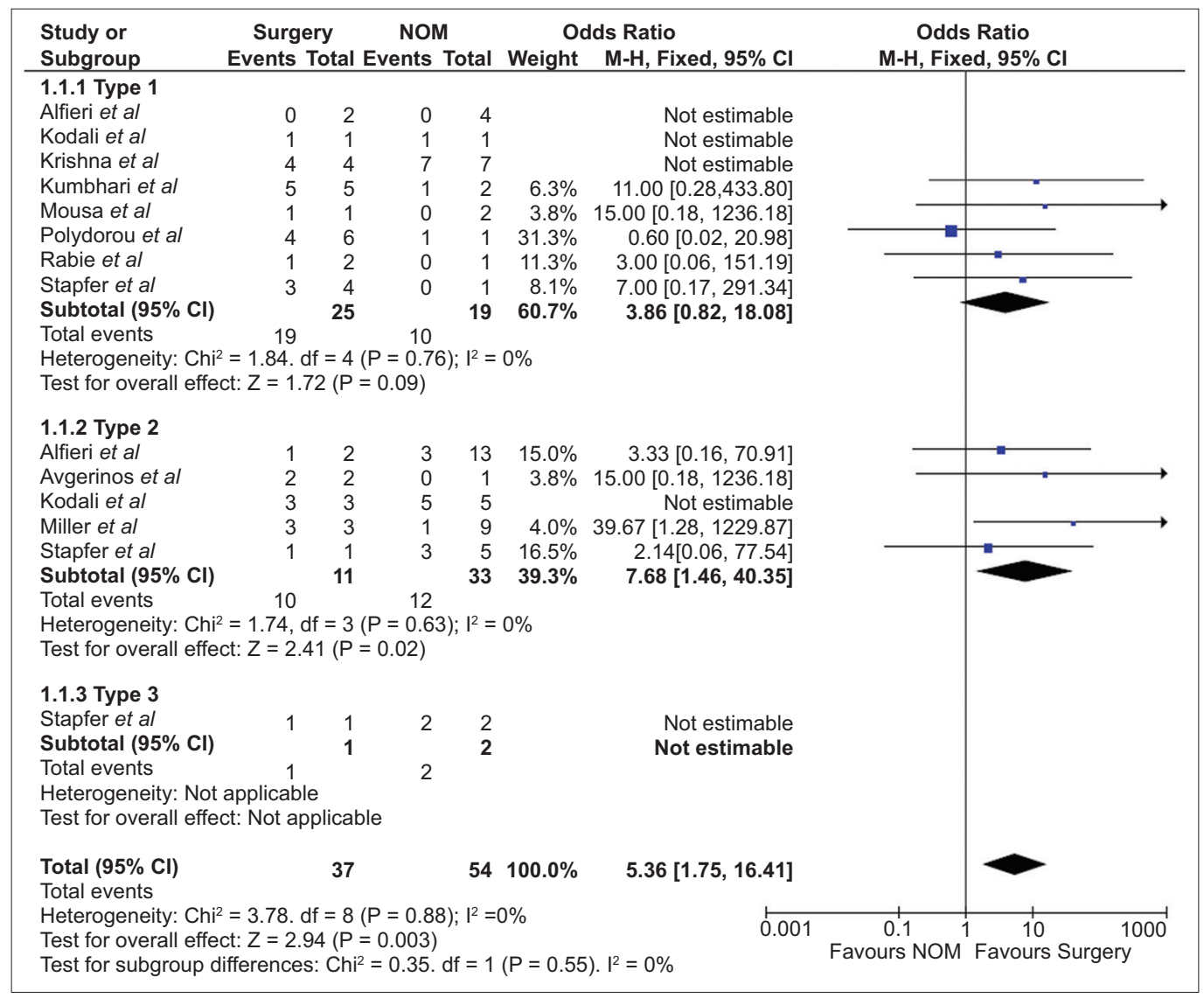

Figure 2 Quantitative analysis of the primary outcome (success of initial management) NOM, non-operative management; CI, confidence interval

perforations following ERCP, and how this is associated with either positive or negative consequences for the patient.
Besides our primary endpoint (success of initial management), mortality and overall length of stay were also reviewed. 
In our systematic review, we used probably the most universally used classification system by Stapfer et al [5]. In concordance with the current literature, in our study type I injuries have the smallest rate of NOM. These patients usually need surgical intervention and, as our results show, the success rate of initial management of post-ERCP perforations in type I patients was considerably higher in the group undergoing initial surgical management when compared to the NOM group (79.5\% and 52.6\%, respectively). Interestingly though, this difference in percentage was not statistically significant.

Type III injuries represent distal bile duct injuries related to wire or basket instrumentation in close proximity to an obstructing entity like a stone, and are often small, while type IV represent pseudo-perforations probably related to the use of compressed air to maintain patency of a lumen, and usually do not require surgical intervention $[19,20]$. All patients with type III and IV injuries included in this meta-analysis had a favorable outcome, whether treated conservatively or surgically.

Last but not least, type II injuries (peri-Vaterian perforation of the medial wall associated with biliary or pancreatic sphincterotomy or precut papillotomy) vary in severity and pose a clinical dilemma. In these patients, an individualized approach is necessary, based on the severity of the perforation and the patient's clinical condition. Moreover, discrimination between type II and IV injuries is sometimes only possible intraoperatively, where after no significant perforation is found, a presumed type II injury is upgraded to type IV. This represents a certain limitation of the current classification system. Nonetheless, in type II perforations a statistically significant difference between the success rate of initial surgical and NOM management was noted, in favor of the former, thus dictating the need for an individualized approach to every case.

Regarding secondary outcomes, there was no statistically significant difference in mortality rates between initial surgical and NOM management for any type of perforation. Similarly, there was no significant difference regarding length of hospital stay between the 2 groups in any of the sub-analyses.

Although the present study is the first meta-analysis regarding the initial management of post-ERCP perforations, the results of our review should be interpreted cautiously. The limitations of the present study reflect the limitations posed by the included studies. The vast majority of the studies were retrospective, while one was a retrospective review of a prospective database. No randomized controlled trials were identified in the current literature, which is a great limitation of this study. The small number of the included studies and the heterogeneity of the included data are also a strong limitation.

In conclusion, the current meta-analysis demonstrated the significance of the initial management of patients with post-ERCP perforations. While there is no consensus as to the management of these patients, when a complication such as perforation occurs, an urgent multidisciplinary meeting should be convened to assess the patient's data and provide a fast and valid treatment plan. Whether a surgical or endoscopic approach is chosen, the patient should immediately be evaluated by an experienced surgeon or endoscopist; if this is not possible they should be urgently referred to a hepatobiliary reference center for treatment.

\section{Summary Box}

\section{What is already known:}

- Perforation following endoscopic retrograde cholangiopancreatography is associated with an estimated incidence ranging from $0.09-1.67 \%$ and mortality up to $8 \%$

- There are only limited and isolated data available related to surgical management, with controversial recommendations on the timing and type of surgical procedures

- Management tends to depend on an individual clinician's preference and expertise

\section{What the new findings are:}

- In type I and II perforations, the success rate of initial surgical management was higher compared to the non-operative management (NOM) group

- There was no statistically significant difference in mortality rates or length of hospital stay between initial surgical and NOM management for any type of perforation

- When a complication such as perforation occurs, an urgent multidisciplinary meeting should take place to assess the patient's data and provide a fast and valid treatment plan

- Whether a surgical or an endoscopic approach is chosen, the patient should immediately be evaluated by an experienced surgeon or endoscopist; if this is not possible they should be urgently referred to a hepatobiliary reference center for treatment

\section{References}

1. Miller R, Zbar A, Klein Y, et al. Perforations following endoscopic retrograde cholangiopancreatography: a single institution experience and surgical recommendations. Am J Surg 2013;206:180-186.

2. Patil NS, Solanki N, Mishra PK, Sharma BC, Saluja SS. ERCPrelated perforation: an analysis of operative outcomes in a large series over 12 years. Surg Endosc 2020;34:77-87.

3. Cirocchi R, Kelly MD, Griffiths EA, et al. A systematic review of the management and outcome of ERCP related duodenal perforations using a standardized classification system. Surgeon 2017;15:379-387.

4. Machado NO. Management of duodenal perforation postendoscopic retrograde cholangiopancreatography. When and whom to operate and what factors determine the outcome? A review article. JOP 2012;13:18-25.

5. Stapfer M, Selby RR, Stain SC, et al. Management of duodenal 
perforation after endoscopic retrograde cholangiopancreatography and sphincterotomy. Ann Surg 2000;232:191-198.

6. Moher D, Liberati A, Tetzlaff J, Altman DG; PRISMA Group. Preferred reporting items for systematic reviews and metaanalyses: the PRISMA statement. PLoS Med 2009;6:e1000097.

7. Higgins JPT, Cochrane Collaboration. Cochrane handbook for systematic reviews of interventions, $2^{\text {nd }}$ ed. Hoboken, WileyBlackwell Publishing Ltd; 2019.

8. NIH. National Heart, Lung, and Blood Institute. Study quality assessment tools. Available from: https://www.nhlbi.nih. gov/health-topics/study-quality-assessment-tools [Accessed 22 September 2021].

9. Mousa HM, Hefny AF, Abu-Zidan FM. Life-threatening duodenal perforation complicating endoscopic retrograde cholangiopanceatography: a case series. Int J Surg Case Rep 2020;66:404-407.

10. Kumbhari V, Sinha A, Reddy A, et al. Algorithm for the management of ERCP-related perforations. Gastrointest Endosc 2016;83:934-943.

11. Kodali S, Mönkemüller K, Kim H, et al. ERCP-related perforations in the new millennium: A large tertiary referral center 10-year experience. United European Gastroenterol J 2015;3:25-30.

12. Rabie ME, Mir NH, Al Skaini MS, et al. Operative and non-operative management of endoscopic retrograde cholangiopancreatographyassociated duodenal injuries. Ann R Coll Surg Engl 2013;95:285-290.

13. Alfieri S, Rosa F, Cina C, et al. Management of duodeno-pancreatobiliary perforations after ERCP: outcomes from an Italian tertiary referral center. Surg Endosc 2013;27:2005-2012.

14. Krishna RP, Singh RK, Behari A, Kumar A, Saxena R, Kapoor VK. Post-endoscopic retrograde cholangiopancreatography perforation managed by surgery or percutaneous drainage. Surg Today 2011;41:660-666.

15. Polydorou A, Vezakis A, Fragulidis G, Katsarelias D, Vagianos C, Polymeneas G. A tailored approach to the management of perforations following endoscopic retrograde cholangiopancreatography and sphincterotomy. J Gastrointest Surg 2011;15:2211-2217.

16. Avgerinos DV, Llaguna OH, Lo AY, Voli J, Leitman IM. Management of endoscopic retrograde cholangiopancreatography: related duodenal perforations. Surg Endosc 2009;23:833-838.

17. Bray MS, Borgert AJ, Folkers ME, Kothari SN. Outcome and management of endoscopic retrograde cholangiopancreatography perforations: A community perspective. Am J Surg 2017;214: 69-73.

18. Frakes JT. The ERCP-related lawsuit: "Best avoid it!". Gastrointest Endosc 2006;63:385-388.

19. Weiser R, Pencovich N, Mlynarsky L, et al. Management of endoscopic retrograde cholangiopancreatography-related perforations: experience of a tertiary center. Surgery 2017;161:920-929.

20. McCarthy CJ, Butros SR, Dawson SL, Arellano RS. Image-guided percutaneous management of duodenal perforation following endoscopic retrograde cholangiopancreatography (ERCP): assessment of efficacy and safety. Clin Radiol 2018;73:319.e9-319.e15. 


\section{Supplementary material}

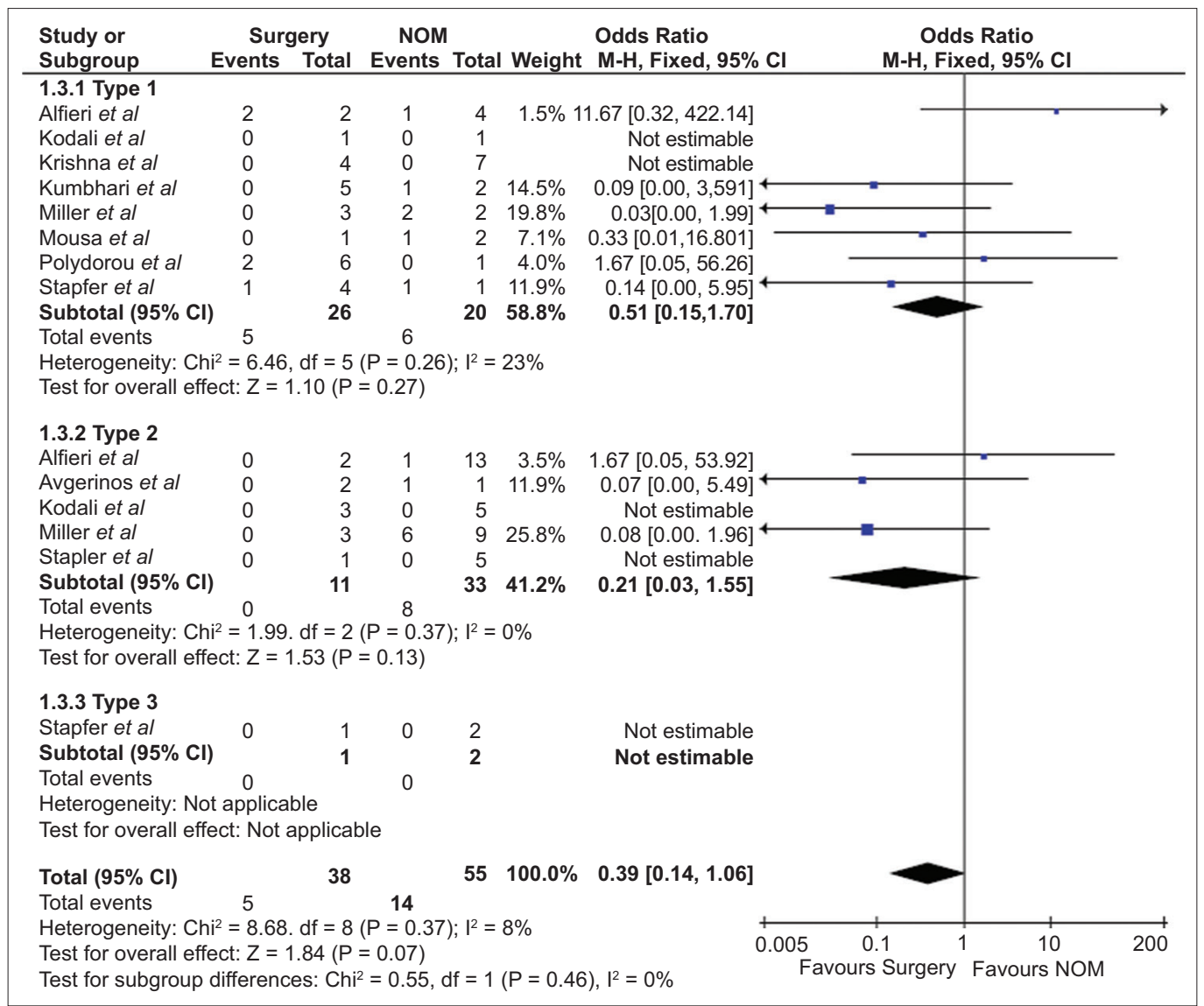

Supplementary Figure 1 Quantitative analysis of mortality rates

NOM, non-operative management; CI, confidence interval

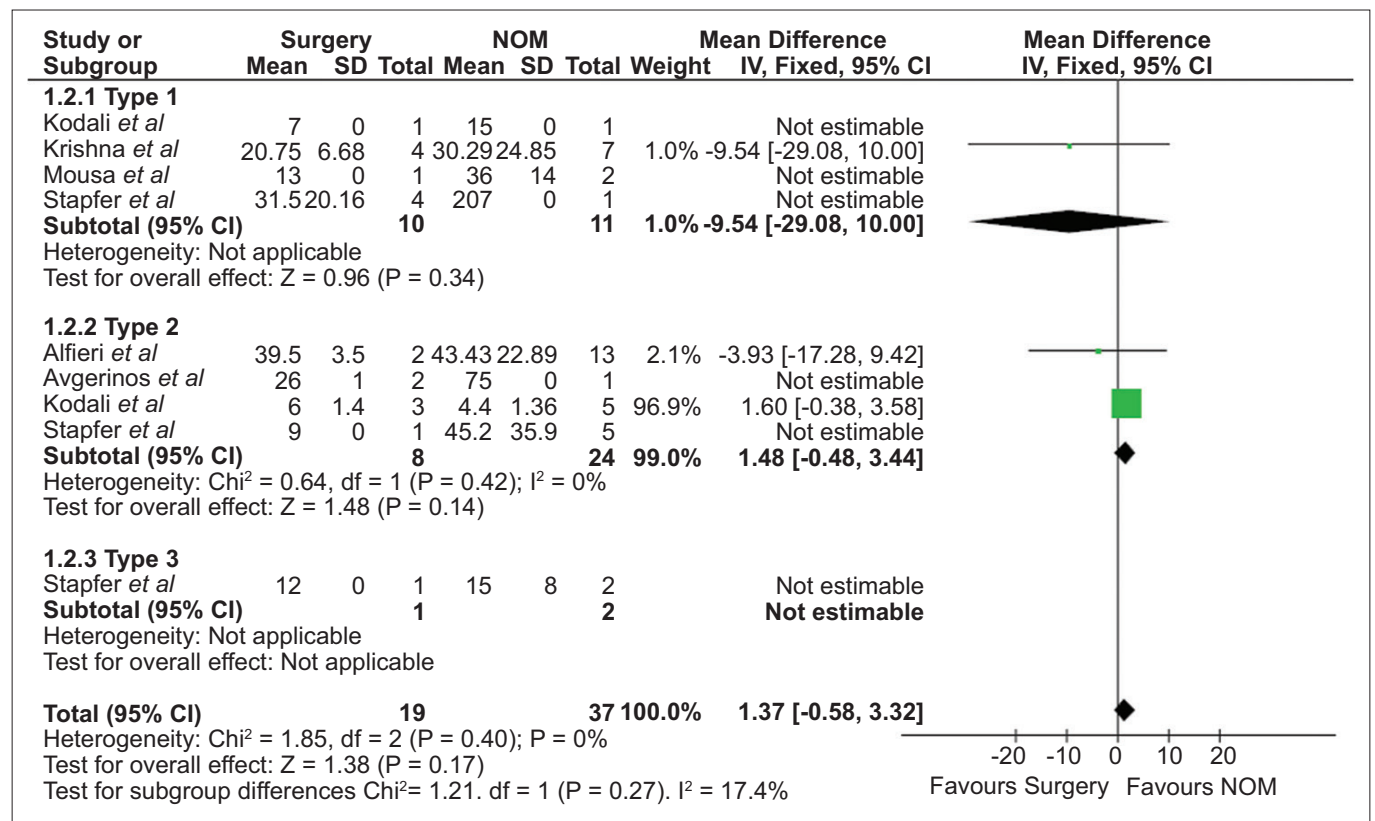

Supplementary Figure 2 Quantitative analysis of length of stay NOM, non-operative management; CI, confidence interval 


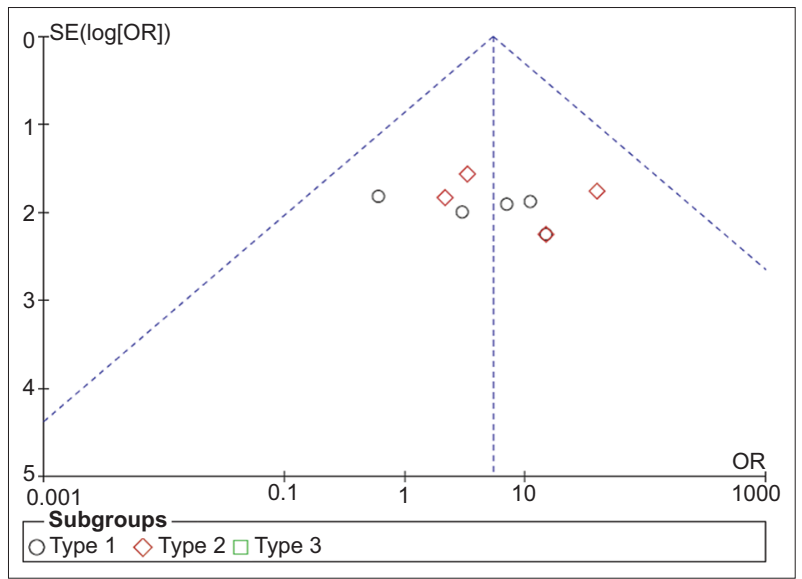

Supplementary Figure 3 Funnel plot of the primary outcome $S E$, standard error; OR, odds ratio

Supplementary Table 1 Type of perforation (Stapfer) and initial management

\begin{tabular}{|c|c|c|c|c|c|c|c|c|c|c|c|c|c|}
\hline \multirow{3}{*}{$\begin{array}{l}\text { First } \\
\text { Author } \\
\text { [Ref.] }\end{array}$} & \multicolumn{12}{|c|}{ Type of perforation (Stapfer) and initial management } & \multirow[t]{3}{*}{ Comments } \\
\hline & \multicolumn{3}{|c|}{1} & \multicolumn{3}{|c|}{2} & \multicolumn{3}{|c|}{3} & \multicolumn{3}{|c|}{4} & \\
\hline & Total & Surgery & NOM & Total & Surgery & NOM & Total & Surgery & NOM & Total & Surgery & NOM & \\
\hline Mousa [10] & 3 & 1 & 2 & 1 & 1 & - & 1 & - & 1 & 1 & - & 1 & - \\
\hline Kumbhari [11] & 7 & 5 & 2 & 54 & - & 54 & - & - & - & - & - & - & - \\
\hline Kodali [12] & 2 & 1 & 1 & 8 & 3 & 5 & 2 & - & 2 & - & - & - & \\
\hline Rabie [13] & 3 & 2 & 1 & 1 & - & 1 & 3 & - & 3 & 3 & - & 3 & - \\
\hline Miller [1] & 5 & 5 & - & 12 & 3 & 9 & 5 & - & 5 & 5 & - & 5 & - \\
\hline Alfieri [14] & 6 & 2 & 4 & 15 & 2 & 13 & 1 & - & 1 & 8 & - & 8 & - \\
\hline Krishna [15] & 11 & 4 & 7 & 1 & 1 & - & 2 & 2 & - & - & - & - & - \\
\hline Polydorou [16] & 7 & 6 & 1 & 30 & - & 30 & 5 & - & 5 & 2 & - & 2 & - \\
\hline Avgerinos [17] & 9 & 9 & - & 3 & 2 & 1 & - & - & - & 1 & - & 1 & $\begin{array}{c}2 \\
\text { unclassified }\end{array}$ \\
\hline Stapfer [7] & 5 & 4 & 1 & 6 & 1 & 5 & 3 & 1 & 2 & - & - & - & - \\
\hline Total & 58 & 39 & 19 & 131 & 13 & 118 & 22 & 3 & 19 & 20 & 0 & 20 & - \\
\hline
\end{tabular}

NOM, non-operative management 


\begin{tabular}{|c|c|c|c|}
\hline \multirow[b]{2}{*}{ Title } & \multicolumn{2}{|r|}{ TITLE } & \multirow[b]{2}{*}{1} \\
\hline & 1 & Identify the report as a systematic review, meta-analysis, or both. & \\
\hline \multirow[b]{2}{*}{ Structured summary } & & ABSTRACT & \\
\hline & 2 & $\begin{array}{l}\text { Provide a structured summary including, as applicable: background; objectives; data } \\
\text { sources; } \\
\text { study eligibility criteria, participants, and interventions; study appraisal and synthesis } \\
\text { methods; results; } \\
\text { limitations; conclusions and implications of key findings; systematic review registration } \\
\text { number. }\end{array}$ & 1 \\
\hline \multirow{3}{*}{$\begin{array}{l}\text { Rationale } \\
\text { Objectives }\end{array}$} & & INTRODUCTION & \\
\hline & 3 & Describe the rationale for the review in the context of what is already known. & 1 \\
\hline & 4 & $\begin{array}{l}\text { Provide an explicit statement of questions being addressed with reference to participants, } \\
\text { interventions, } \\
\text { comparisons, outcomes, and study design (PICOS). }\end{array}$ & $1-2$ \\
\hline \multicolumn{3}{|r|}{ METHODS } & \\
\hline Protocol and registration & 5 & $\begin{array}{l}\text { Indicate if a review protocol exists, if and where it can be accessed (e.g., Web address), } \\
\text { and, if } \\
\text { available, provide registration information including registration number. }\end{array}$ & 2 \\
\hline Eligibility criteria & 6 & $\begin{array}{l}\text { Specify study characteristics (e.g., PICOS, length of follow up) and report characteristics } \\
\text { (e.g., years } \\
\text { considered, language, publication status) used as criteria for eligibility, giving rationale. }\end{array}$ & 2 \\
\hline Information sources & 7 & $\begin{array}{l}\text { Describe all information sources (e.g., databases with dates of coverage, contact with study } \\
\text { authors } \\
\text { to identify additional studies) in the search and date last searched. }\end{array}$ & 2 \\
\hline Search & 8 & $\begin{array}{l}\text { Present full electronic search strategy for at least one database, including any limits used, } \\
\text { such that it } \\
\text { could be repeated. }\end{array}$ & 2 \\
\hline Study selection & 9 & $\begin{array}{l}\text { State the process for selecting studies (i.e., screening, eligibility, included in systematic } \\
\text { review, and, } \\
\text { if applicable, included in the meta-analysis). }\end{array}$ & 2 \\
\hline Data collection process & 10 & $\begin{array}{l}\text { Describe method of data extraction from reports (e.g., piloted forms, independently, in } \\
\text { duplicate) and } \\
\text { any processes for obtaining and confirming data from investigators. }\end{array}$ & 2 \\
\hline Data items & 11 & $\begin{array}{l}\text { List and define all variables for which data were sought (e.g., PICOS, funding sources) and } \\
\text { any } \\
\text { assumptions and simplifications made. }\end{array}$ & 2 \\
\hline $\begin{array}{l}\text { Risk of bias in individual } \\
\text { studies }\end{array}$ & 12 & $\begin{array}{l}\text { Describe methods used for assessing risk of bias of individual studies (including } \\
\text { specification of } \\
\text { whether this was done at the study or outcome level), and how this information is to be } \\
\text { used in any } \\
\text { data synthesis. }\end{array}$ & 2 \\
\hline Summary measures & 13 & State the principal summary measures (e.g., risk ratio, difference in means). & 2 \\
\hline Synthesis of results & 14 & $\begin{array}{l}\text { Describe the methods of handling data and combining results of studies, if done, including } \\
\text { measures } \\
\text { of consistency }\left(\text { e.g., } I^{2}\right) \text { for each meta-analysis. }\end{array}$ & 2 \\
\hline Risk of bias across studies & 15 & $\begin{array}{l}\text { Specify any assessment of risk of bias that may affect the cumulative evidence (e.g., } \\
\text { publication bias, } \\
\text { selective reporting within studies). }\end{array}$ & 2 \\
\hline Additional analyses & 16 & $\begin{array}{l}\text { Describe methods of additional analyses (e.g., sensitivity or subgroup analyses, } \\
\text { meta-regression), } \\
\text { if done, indicating which were pre-specified. }\end{array}$ & $\mathrm{n} / \mathrm{a}$ \\
\hline
\end{tabular}




\begin{tabular}{|c|c|c|c|}
\hline Section/topic & \# & Checklist item & $\begin{array}{l}\text { Reported } \\
\text { on page \# }\end{array}$ \\
\hline \multicolumn{4}{|c|}{ RESULTS } \\
\hline Study selection & 17 & $\begin{array}{l}\text { Give numbers of studies screened, assessed for eligibility, and included in the review, with } \\
\text { reasons } \\
\text { for exclusions at each stage, ideally with a flow diagram. }\end{array}$ & 2 \\
\hline Study characteristics & 18 & $\begin{array}{l}\text { For each study, present characteristics for which data were extracted (e.g., study size, } \\
\text { PICOS, } \\
\text { follow-up period) and provide the citations. }\end{array}$ & 2 \\
\hline Risk of bias within studies & 19 & $\begin{array}{l}\text { Present data on risk of bias of each study and, if available, any outcome level assessment } \\
\text { (see item 12). }\end{array}$ & 2,4 \\
\hline $\begin{array}{l}\text { Results of individual } \\
\text { studies }\end{array}$ & 20 & $\begin{array}{l}\text { For all outcomes considered (benefits or harms), present, for each study: (a) simple } \\
\text { summary data for } \\
\text { each intervention group (b) effect estimates and confidence intervals, ideally with a forest } \\
\text { plot. }\end{array}$ & $2-3$ \\
\hline Synthesis of results & 21 & $\begin{array}{l}\text { Present results of each meta-analysis done, including confidence intervals and measures of } \\
\text { consistency. }\end{array}$ & 4 \\
\hline Risk of bias across studies & 22 & Present results of any assessment of risk of bias across studies (see Item 15). & 2,4 \\
\hline Additional analysis & 23 & $\begin{array}{l}\text { Give results of additional analyses, if done (e.g., sensitivity or subgroup analyses, } \\
\text { meta-regression } \\
\text { [see Item 16]). }\end{array}$ & $\mathrm{n} / \mathrm{a}$ \\
\hline \multicolumn{4}{|c|}{ DISCUSSION } \\
\hline Summary of evidence & 24 & $\begin{array}{l}\text { Summarize the main findings including the strength of evidence for each main outcome; } \\
\text { consider } \\
\text { their relevance to key groups (e.g., healthcare providers, users, and policy makers). }\end{array}$ & 6 \\
\hline Limitations & 25 & $\begin{array}{l}\text { Discuss limitations at study and outcome level (e.g., risk of bias), and at review-level (e.g., } \\
\text { incomplete } \\
\text { retrieval of identified research, reporting bias). }\end{array}$ & 6 \\
\hline Conclusions & 26 & $\begin{array}{l}\text { Provide a general interpretation of the results in the context of other evidence, and } \\
\text { implications for } \\
\text { future research. }\end{array}$ & 6 \\
\hline \multicolumn{4}{|c|}{ FUNDING } \\
\hline Funding & 27 & $\begin{array}{l}\text { Describe sources of funding for the systematic review and other support (e.g., supply of } \\
\text { data); role of funders for the systematic review. }\end{array}$ & $\mathrm{n} / \mathrm{a}$ \\
\hline
\end{tabular}

